\title{
Respiratory effects of kynurenic acid microinjected into the ventromedullary surface of the rat
}

\section{F.P. Tolentino-Silva, \\ A.K. Russo, \\ S.L. Cravo and \\ O.U. Lopes}

Departamento de Fisiologia, Escola Paulista de Medicina,

Universidade Federal de São Paulo, São Paulo, SP, Brasil

\section{Correspondence}

F.P. Tolentino-Silva

Departamento de Fisiologia

EPM, UNIFESP

Rua Botucatu, 862

04023-060 São Paulo, SP

Brasil

Fax: + 55-11-573-7820

E-mail: ftolentino.fisi@epm.br

Research supported by FAPESP.

Received April 8, 1997

Accepted July 6, 1998

\section{Abstract}

Several studies demonstrate that, within the ventral medullary surface (VMS), excitatory amino acids are necessary components of the neural circuits involved in the tonic and reflex control of respiration and circulation. In the present study we investigated the cardiorespiratory effects of unilateral microinjections of the broad spectrum glutamate antagonist kynurenic acid $(2 \mathrm{nmol} / 200 \mathrm{nl})$ along the VMS of urethaneanesthetized rats. Within the VMS only one region was responsive to this drug. This area includes most of the intermediate respiratory area, partially overlapping the rostral ventrolateral medulla (IA/RVL). When microinjected into the IA/RVL, kynurenic acid produced a respiratory depression, without changes in mean arterial pressure or heart rate. The respiratory depression observed was characterized by a decrease in ventilation, tidal volume and mean inspiratory flow and an increase in respiratory frequency. Therefore, the observed respiratory depression was entirely due to a reduction in the inspiratory drive. Microinjections of vehicle (200 $\mathrm{nl}$ of saline) into this area produced no significant changes in breathing pattern, blood pressure or heart rate. Respiratory depression in response to the blockade of glutamatergic receptors inside the rostral VMS suggests that neurons at this site have an endogenous glutamatergic input controlling the respiratory cycle duration and the inspiratory drive transmission.

The ventral medullary surface (VMS) is widely considered to be an important site for the integration of many autonomic and somatic functions including the respiratory and cardiovascular control $(1,2)$. Within the VMS, three areas essential for the respiratory activity (rostral, intermediate and caudal) (3) coexist with sites responsible for the generation and maintenance of the vasomotor tone and arterial blood pressure regulation: the
Key words

- Ventral surface of the medulla

- Breathing pattern

- Cardiorespiratory control

- Kynurenic acid

- Rat rostral ventrolateral medulla (RVL), caudal ventrolateral medulla (CVL) $(4,5)$ and the caudal pressor area (CPA) (6-8). The RVL overlaps most of the intermediate area, whereas CVL overlaps the caudal respiratory area. Although CPA stimulation produces a well-defined respiratory activation (9), so far this response has not been related to any particular respiratory area.

Although the localization of these respi- 
ratory and cardiovascular areas in the VMS is well established, the neurotransmitters involved in these circuits remain largely unknown. Several studies indicate that excitatory amino acids are significant components of the neural circuits involved in the generation and maintenance of the respiratory rhythm and vasomotor tone $(10,11)$. Topical application to (12) or microinjections $(9,13)$ of L-glutamate into the ventrolateral medullary surface elicit pronounced changes in respiration and arterial blood pressure. In a previous study (9) we demonstrated that, in the rat, three different breathing patterns could be elicited from four distinct sites within the VMS. When applied to the RVL or the CPA, L-glutamate produced increases in ventilation, inspiratory drive and hypertension. Within the CVL two respiratory patterns were observed: microinjection into the rostral half of the CVL produced respiratory depression, while in the caudal half increases in minute ventilation and inspiratory drive were associated with bradypnea. Whether all of these areas represent sites of tonic respiratory activity remains undetermined.

To further characterize the role of glutamatergic afferents present in the VMS in respiratory control, in the present study we investigated the effects of microinjections of the broad spectrum glutamate antagonist kynurenic acid on the breathing pattern, arterial blood pressure and heart rate of anesthetized rats.

Experiments were performed on male Wistar rats $(\mathrm{N}=25)$ weighing $300 \pm 6 \mathrm{~g}$ anesthetized with urethane $(1.2 \mathrm{~g} / \mathrm{kg}$, ip $)$, tracheotomized and placed in a closed cylinder-shaped body plethysmograph $(80 \mathrm{~mm}$ ID, $300 \mathrm{~mm}$ long) with openings at both ends to allow the externalization of the head, thermal probe, and arterial and venous catheters. Respiratory flow was recorded with a pneumotachometer (Fleisch No. 0000) connected to the plethysmograph. After amplification and analog to digital conversion, the signal was computer-processed to quantify the parameters of the respiratory pattern (ventilation, $\mathrm{VE}_{\mathrm{E}}$; tidal volume, $\mathrm{VT}_{\mathrm{T}}$; inspiratory time, $\mathrm{T}$; expiratory time, $\mathrm{T}_{\mathrm{E}}$; breathing frequency, f; mean inspiratory flow, $\mathrm{VT}_{\mathrm{T}} \mathrm{TI}$ ). Mean arterial pressure (MAP) and heart rate (HR) were monitored continually throughout the experiment using a Statham transducer $(\mathrm{P} 23$ $\mathrm{Db}$ ) connected to the femoral artery, coupled to a Beckman R-611 polygraph. The animals were placed prone in a stereotaxic frame (Stoelting) and temperature was maintained at $37^{\circ} \mathrm{C}$. Kynurenic acid (KA, $\left.2 \mathrm{nmol} / 200 \mathrm{nl}\right)$ was unilaterally microinjected into the VMS according to a method previously described (8). This method consistently allowed injections to be placed inside the ventral surface. Each animal received one to three microinjections, at least $2 \mathrm{~mm}$ apart, distributed at random along the VMS. A new site was tested only after the effect of a previous microinjection had completely disappeared. At the end of the experiments the last injection site was marked with $200 \mathrm{nl}$ of $2 \%$ Evan's blue dye. The animals were sacrificed with an overdose of urethane, and the brainstem was removed and fixed in $10 \%$ formaldehyde. Injection sites were identified and plotted on a schematic diagram. Other sites tested in the experiment were plotted according to their relative position with respect to the site marked with the dye. To further identify injection sites, the brainstem was also cut coronally into $40-\mu \mathrm{m}$ thick sections and stained with $1 \%$ neutral red. Photomicrographs and schematic drawings of typical injection sites obtained with this method have been presented elsewhere (9). The breath-by-breath respiratory pattern data for each animal were interpolated at 15-s intervals. All data are reported as means \pm SEM. Friedman's analysis of variance was used to test whether or not values changed with time after glutamate microinjection, with subsequent post hoc comparisons by Dunnett's test. The criterion for statistical significance was $\mathrm{P}<0.05$. 
The distribution of responsive sites was systematically explored within the VMS by examining respiratory responses to unilateral microinjections of KA $(2 \mathrm{nmol} / 200 \mathrm{nl})$ at 74 points. The area explored extended from $6 \mathrm{~mm}$ rostral to $2.5 \mathrm{~mm}$ caudal to the calamus scriptorius (CS) and up to $4 \mathrm{~mm}$ lateral to the midline. The area surveyed is illustrated in Figure 1. Active respiratory sites, i.e., sites where KA produced significant changes in respiration, were found in the VMS in an area lying 2.3 to $3.8 \mathrm{~mm}$ rostral and 1.5 to $2.5 \mathrm{~mm}$ lateral to the CS (Figure 1). The time course and percentile changes of respiratory parameters are presented in Figure 2. Before KA, ventilation was $113 \pm 9.6 \mathrm{ml} / \mathrm{min}$, tidal volume was 1.5 $\pm 0.1 \mathrm{ml}$ and $\mathrm{V}$ T/Tiwas $4.9 \pm 0.6 \mathrm{ml} / \mathrm{s}(\mathrm{N}=9)$. Sixty seconds after KA administration, ventilation was decreased by $27 \pm 4.2 \%$, tidal volume by $38 \pm 4.1 \%$ and $\mathrm{VT}_{\mathrm{T}} \mathrm{T}_{\mathrm{I}}$ by $32 \pm$ $4.0 \%$. Respiratory depression was accompanied by a $19 \pm 3.7 \%$ increase in respiratory frequency (control $=81 \pm 7.2$ breaths $/ \mathrm{min}$ ). Therefore, the observed respiratory depression was entirely due to reduction in inspiratory drive. Although a progressive reduction in both inspiratory and expiratory times was observed, these reductions did not reach levels of statistical significance (Table 1, Figure 2). No significant changes in MAP or HR were observed (basal: 101.3 \pm 7.6 and $389 \pm$ $0.1 ; 60 \mathrm{~s}$ after KA: $106.9 \pm 2.3 \mathrm{mmHg}$ and $390 \pm 0.1$ beats/min, respectively). Microinjection of vehicle ( $200 \mathrm{nl}$ of saline) into this area produced no significant changes in any of the parameters analyzed.

Previously (9), using unilateral microinjections of L-glutamate, we have demonstrated the presence of cardiorespiratory active sites along a column in the VMS extending from the VI cranial nerve to the first cervical nerves in the caudal medulla. The results obtained in the present study demonstrate that within the VMS only in the region of the intermediate respiratory area overlapping the rostral ventrolateral medulla (IA/
RVL), unilateral microinjections of KA produced a reduction in ventilation without changing blood pressure or heart rate. Taken together, these data indicate that only in the IA/RVL are tonically active glutamatergic inputs required to control inspiratory drive and respiratory cycle duration.

Previous studies (10) reported that in

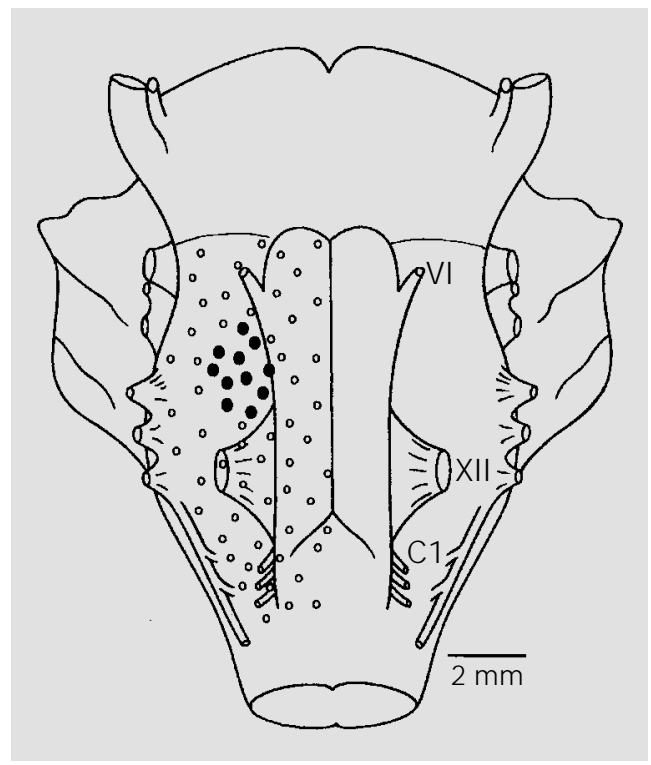

Figure 1 - The diagram represents the ventral medullary surface of the rat summarizing results obtained from 74 microinjections in 25 animals. Filled circles indicate sites where unilateral microinjections of kynurenic acid produced decreases in ventilation, tidal volume and inspiratory drive concurrently with tachypnea, whereas the small open dots indicate sites where no significant respiratory changes were obtained. For clarity all microinjections are represented on the left side regardless of the actual side of application. $\mathrm{C}_{1}=$ First cervical nerve, $\mathrm{VI}$ and $\mathrm{XII}=6$ th and 12 th cranial nerve rootlets, respectively.

Table 1 - Cardiorespiratory responses produced by unilateral microinjections of kynurenic acid into the ventrolateral medulla.

$\dot{V}_{E}$, Ventilation; $V_{T}$, tidal volume; $T$, inspiratory time; $T E$, expiratory time; $f$, breathing frequency; $\mathrm{V} T / \mathrm{T}$, mean inspiratory flow; MAP, mean arterial pressure; $\mathrm{HR}$, heart rate; $\mathrm{N}$, number of injection points. All values are reported as means $\pm \mathrm{SEM}$. Responses to kynurenic acid are reported as percent change in relation to the control value. $N=11$. $* P<0.05$ compared to control (Friedman's analysis of variance).

\begin{tabular}{|c|c|c|c|c|c|}
\hline \multirow[t]{2}{*}{ Time } & \multirow[t]{2}{*}{ Control } & \multicolumn{4}{|c|}{$\%$ Change } \\
\hline & & $15 \mathrm{~s}$ & $30 s$ & $45 \mathrm{~s}$ & $60 s$ \\
\hline MAP $(\mathrm{mmHg})$ & $101.3 \pm 7.6$ & $+5.1 \pm 2.3$ & $+5.6 \pm 2.3$ & $+5.6 \pm 2.3$ & $+5.6 \pm 2.3$ \\
\hline HR (beats/min) & $389 \pm 0.1$ & $+0.1 \pm 0.1$ & $+0.1 \pm 0.1$ & $+0.1 \pm 0.1$ & $+0.1 \pm 0.1$ \\
\hline f (breaths/min) & $81 \pm 7.2$ & $+3.7 \pm 1.2$ & $+8.5 \pm 1.4^{*}$ & $+8.1 \pm 2.0^{*}$ & $+18.6 \pm 3.7^{*}$ \\
\hline $\mathrm{V} T(\mathrm{ml})$ & $1.5 \pm 0.1$ & $-15.5 \pm 2.5^{*}$ & $-23.1 \pm 3.1^{*}$ & $-31.0 \pm 3.2^{*}$ & $-37.8 \pm 4.1^{*}$ \\
\hline$\dot{V}_{E}(\mathrm{ml} / \mathrm{min})$ & $113.4 \pm 9.6$ & $-11.9 \pm 2.0^{*}$ & $-17.2 \pm 3.4^{*}$ & $-24.9 \pm 3.4^{*}$ & $-26.7 \pm 4.2^{*}$ \\
\hline$T_{1}(s)$ & $0.32 \pm 0.02$ & $-5.6 \pm 6.6$ & $-13.1 \pm 6.2$ & $-10.1 \pm 4.1$ & $-10.1 \pm 4.1$ \\
\hline TE (s) & $0.50 \pm 0.06$ & $-1.6 \pm 4.8$ & $-1.5 \pm 5.7$ & $-11.9 \pm 4.9$ & $-16.2 \pm 5.8$ \\
\hline $\mathrm{V} T / \mathrm{Tl}(\mathrm{ml} / \mathrm{s})$ & $4.9 \pm 0.6$ & $-6.8 \pm 4.9$ & $-13.9 \pm 3.9 *$ & $-25.9 \pm 4.8^{*}$ & $-32.2 \pm 4.0^{*}$ \\
\hline
\end{tabular}


Figure 2 - Time course of changes (mean \pm SEM, \% of control) in ventilation ( $(\mathrm{E})$, tidal volume $\left(\mathrm{V}_{\mathrm{T}}\right)$, respiratory frequency (f), inspiratory time ( $\mathrm{T}_{\mathrm{I}}$, expiratory time ( $\left.T_{E}\right)$ and mean inspiratory flow $\left(\mathrm{V}_{T} / T_{\mathrm{I}}\right)$ elicited by unilateral microinjection of kynurenic acid $(2 \mathrm{nmol} / 200 \mathrm{nl})$ into responsive sites of the ventrolateral medulla. $* \mathrm{P}<0.05 \mathrm{com}$ pared to control (Friedman's analysis of variance).

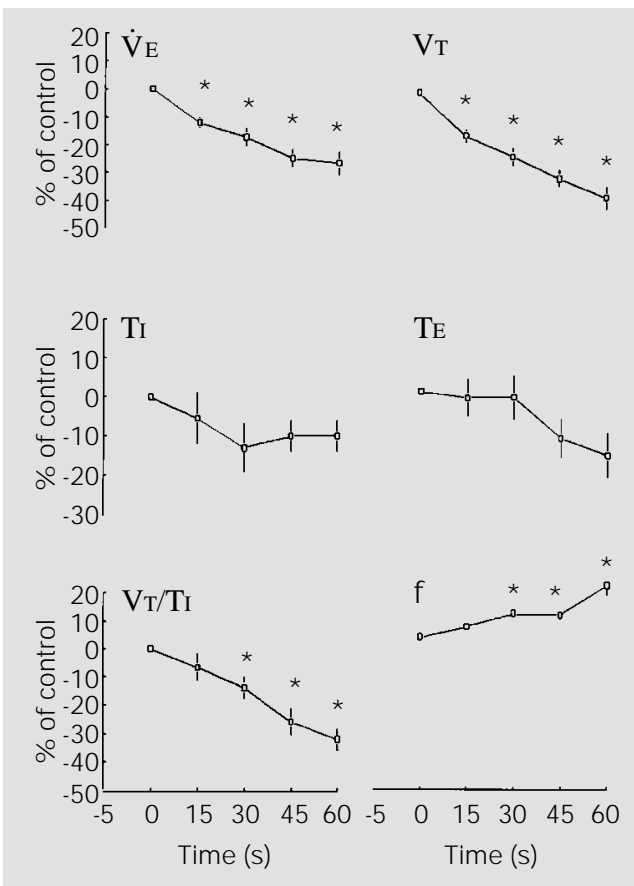

anesthetized vagotomized rats, bilateral microinjection of KA (45 mM) into an area equivalent to the IA/RVL here described produced a $42 \%$ reduction in phrenic nerve activity and a $27 \%$ increase in frequency, simultaneously with a $15-\mathrm{mmHg}$ hypotension. Similar results were also obtained in other species. In cats, bilateral microinjections of KA into the IA/RVL resulted in reduction of $\mathrm{VT}_{\mathrm{T}}$ and a rise in respiratory frequency (14). This respiratory depression was associated with a reduction in phrenic nerve activity with a decrease in the respiratory cycle timing (15). Similarly to the results obtained here, in these studies KA produced minor or no alteration in mean arterial pressure or heart rate. Chemical or electrolytic inactivation of neurons in this area re- sulted in apnea and decreased $\mathrm{CO}_{2}$ sensitivity in cats (16) or rabbits (17).

All of these studies were restricted to the IA/RVL area. Our study demonstrated that in this area even unilateral blockade of glutamatergic afferents is capable of producing significant reductions in ventilation. Contrarily, in caudal portions of the VMS (including the caudal respiratory area overlapping the caudal ventrolateral medulla and the caudal pressor area) unilateral glutamatergic blockade was unable to modify respiration, even though these areas are responsive to glutamate stimulation (9).

The local circuitry and the synaptic mechanisms underlying the IA/RVL control of respiratory rithmogenesis remain largely unknown. Neurons in this area are extensively connected to both the dorsal and ventral respiratory groups (18) and represent the link between the generators of respiratory rhythm and vasomotor tone (10). Recently Smith et al. (19) suggested that neurons in the pre-Böotzinger complex, an area partially overlapping the IA/RVL region, require glutamatergic inputs to maintain the membrane potential in the range for the intrinsic oscillations adequate for the spontaneous activity and the mutual excitatory interactions present in these cells. The origin of these glutamatergic afferents remains unknown.

In conclusion, although several sites involved in the regulation of inspiratory drive and timing mechanisms can be stimulated by L-glutamate within the VMS, glutamatergic inputs have a relevant tonic activity only in the IA/RVL region.

\section{References}

1. Pilowsky PM, West MJ \& Chalmers JP (1985). Renal sympathetic nerve response to stimulation, inhibition and destruction of the ventrolateral medulla in the rabbit. Neuroscience Letters, 60: 51-55.

2. McAllen RM (1986). Location of neurones with cardiovascular and respiratory func- tion at the ventral surface of the cat medulla. Neuroscience, 18: 43-49.

3. Schlaefke ME (1981). Central chemosensitivity: a respiratory drive. Reviews of Physiology, Biochemistry and Pharmacology, 90: 171-244.

4. Guertzenstein PG \& Silver A (1974). Fall in blood pressure produced from discrete regions of the ventral surface medulla by glycine and lesions. J ournal of Physiology, 242: 489-503.

5. Feldberg W \& Guertzenstein PG (1976). Vasodepressor effects obtained by drugs acting on the ventral surface of the brain 
stem. J ournal of Physiology, 258: 337355.

6. Gordon FJ \& McCann LA (1988). Pressor responses evoked by microinjections of kynurenic acid into caudal ventrolateral medulla of the rats. Brain Research, 457: 251-258.

7. Campos J r RR, Possas OS, Cravo SL, Lopes OU \& Guertzenstein PG (1994). Putative pathways involved in cardiovascular responses evoked from the caudal pressor area. Brazilian J ournal of Medical and Biological Research, 27: 2467-2479.

8. Possas OS, Campos J r RR, Cravo SL, Lopes OU \& Guertzenstein PG (1994). A fall in arterial blood pressure produced by inhibition of the caudalmost ventrolateral medulla: the caudal pressor area. J ournal of the Autonomic Nervous System, 49: 235-245.

9. Tolentino-Silva FP, Campos RR, Russo AK, Cravo SL \& Lopes OU (1997). Cardiorespiratory effects of L-glutamate microinjected into the rat ventral medulla. Respiration Physiology, 108: 23-33.

10. Guyenet PG, Darnall RA \& Riley TA (1990). Rostral ventrolateral medulla and sympathorespiratory integration in rats. Ameri- can J ournal of Physiology, 259: R1063R1074.

11. Funk GD, Smith CJ \& Feldman J L (1994). Generation and transmission of respiratory oscillations in medullary slices: role of excitatory amino acids. J ournal of Neurophysiology, 70: 1497-1515.

12. Mitra J, Prabhakar NR, Overholt JL \& Cherniack NS (1989). Respiratory effects of N-methyl-D-aspartate on the ventrolateral medullary surface. J ournal of Applied Physiology, 67: 1814-1819.

13. McCrimmon DR, Feldman J L \& Speck DF (1986). Respiratory motoneuronal activity is altered by injections of picomoles of glutamato into cat brain stem. J ournal of Neuroscience, 6: 2384-2392.

14. Abrahams TP, Hornby PJ, Walton DP, Taveira DaSilva AM \& Gillis RA (1991). An excitatory amino acid(s) in the ventrolateral medulla is (are) required for breathing to occur in the anesthetized cat. J ournal of Pharmacology and Experimental Therapeutics, 259: 1388-1395.

15. Nattie EE, Gdovin M \& Li A (1993). Retrotrapezoid nucleus glutamate receptors: control of $\mathrm{CO}_{2}$-sensitive phrenic and sympathetic output. J oumal of Applied Physi- ology, 74: 2958-2968.

16. St. J ohn WM , Hwang Q, Nattie EE \& Zhou D (1989). Functions of the retrofacial nucleus in chemosensitivity and ventilatory neurogenesis. Respiration Physiology, 76: 159-172.

17. Zhang F, Wu Z \& Li Y (1991). Effects of blocking medial area of nucleus retrofacialis on respiratory rhythm. Respiration Physiology, 85: 73-81.

18. Smith J C, Morrison DE, Ellenberger $\mathrm{HH}$, Otto MR \& Feldman J L (1989). Brainstem projections to the major respiratory neuron populations in the medulla of the cat. J ournal of Comparative Neurology, 281: 69-96.

19. Smith J C, Funk GD, J ohnson SM \& Feldman J L (1995). Cellular and synaptic mechanisms generating respiratory rhythm: insights from in vitro and computational studies. In: Trouth CO, Millis RM, Kiwull-Schöne HF \& Schläfke ME (Editors), Ventral Brainstem Mechanisms and Control of Respiration and Blood Pressure. Marcell Deker, Inc., New York, NY, 463-496. 